\title{
Numerical analysis of progressive collapse performance of reinforced concrete frame under blast loading
}

\author{
SU Zhi-bo ${ }^{a}, H U$ Qi-gao ${ }^{b},{ }^{*} Z H A N G$ Fan-zhen ${ }^{c}$, BU Jie, HE Mi-jian \\ National University of Defense Technology, Changsha 410072, China \\ a570639649@qq.com, ${ }^{\mathrm{b}}$ 13308492472@189.cn, ${ }^{\mathrm{a}}$ zhangfanzhen7@163.com
}

\begin{abstract}
Keywords: blast load; reinforced concrete frame; progressive collapse; numerical simulation; critical load; dynamic amplification factor.

Abstract. Under blast load, the progressive collapse performance of reinforced concrete structures is very complex. This article gives a more applicative and efficient RC frame structure model by ANSYS/LS-DYNA, and studies the effects of concrete strength and longitudinal reinforcement ratio to progressive collapse performance by parametric analysis, then calculates the critical load and dynamic amplification factor. It is found that the progressive collapse resistant capacity can improve with the concrete strength and longitudinal reinforcement ratio, the critical load of the frame structure is 3.15 times of the design load, and the dynamic amplification factor is 1.32.
\end{abstract}

\section{Introduction}

Collapse of buildings causing by blast occurs with an increasing frequency in the past 30 years, especially the continuous collapse of buildings has attracted more attention. The explosion caused by terrorist attacks or other factors can easily lead to the progressive collapse which causes enormous losses. In 1993, a gas explosion at an 18-floor apartment in Ronan Point, England, caused the progressive collapse of part of the building because of the chain reaction ${ }^{[1]}$. In 1995, Alfred P. Murrah Federal Building in Ohio was hit by a truck bomb, causing progressive collapse of the structure, 168 people were killed ${ }^{[2]}$. It is well known that Catastrophic consequences were caused by ' 911 ' incident in the United State. The RC structures are widely used all over the world, the study of its progressive collapse performance under blast loading is important to avoid continuous collapse.

Related researches on structural collapse performance under blast loading have been carried out by domestic and foreign scholars. Li zhongxian, Shi Yanchao ${ }^{[3-4]}$ have studied the dynamic response and failure mode of the RC slabs and columns under blast loading, and a new advanced method in the progressive collapse of RC frame was proposed; The slab-column structure alternative load path and the force transmission mechanism were studied by Yi Weijian ${ }^{[5]}$ using a quasi-static experimental method to simulate the sudden column loss, the experimental results show that good ability of deformation and progressive collapse resistant of RC slab-column structure can be given by the perfect designing and structural measures. The anti-collapse performance of $\mathrm{RC}$ frame structures was studied by He qingfeng ${ }^{[6]}$. The blast loading is complex, the experiments of blast are difficult and are limited in number, and accurate numerical simulation is too difficult. Applicative and efficient RC frame structure model was proposed in this study to agree with the experiment conducted by $\mathrm{He}$ qingfeng, then the effects of concrete strength and longitudinal reinforcement ratio on progressive collapse performance are investigated, the critical load and dynamic amplification factor are calculated.

\section{Model Establishment.}

The experimental conditions and parameters of frame are presented in reference [6].The experimental frame is shown in fig.1 (a), and the loss column (ZB3 for short) is shown in fig.1 (b) and fig.1 (c) where marked by ellipse.

The discrete model is used to treat steel and concrete as different elements, the workload of establishing the model is heavy, the computing time is long and hard to converge when the amount of reinforcing bar is huge and the layout is complex. Steel element is thought to distribute in the whole 
element, and the reinforced concrete is thought as a homogeneous continuous composite material in the smeared model, there are less elements and the amount of calculation is small in this way. The model is large and the reinforcing bar is complex in this study, so the smeared model is adopted to improve the calculative efficiency.

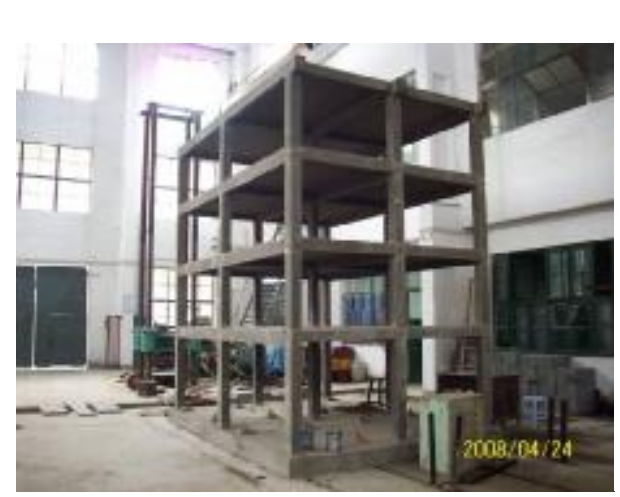

(a) Frame structure

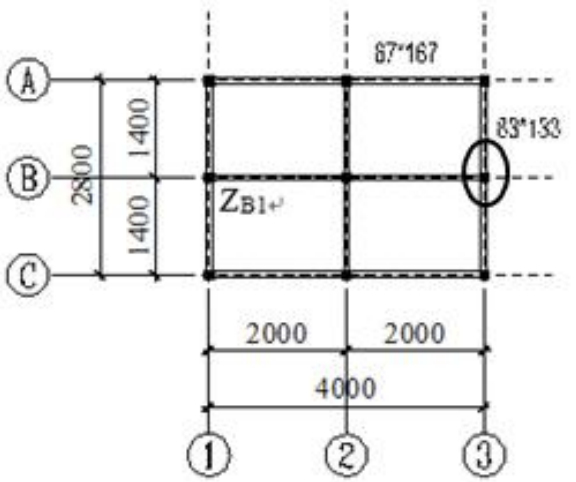

(c) Elevation

(b) Plan

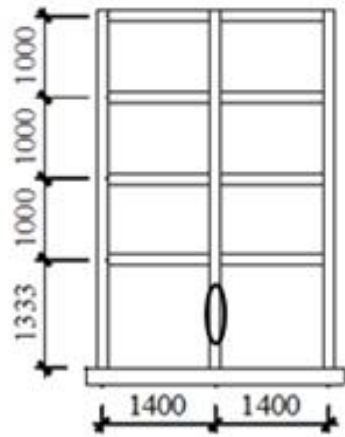

Fig.1Basic form of frame structure

Element SOLID164 which used to show 3D entity is suitable for the RC smeared model. 1 point integration and hourglass control are chosen in order to avoid long computing time causing multi-point integration. The mesh size of the whole model is $30 \mathrm{~mm}$, but the mesh size of the slabs is 15mm.MAT-BRITTLE-DAMAGE (Type 96) is widely used in the RC smeared model. Material parameters used in this study are shown in Table 1 and Table 2 (the Strength is short for Cube Compressive Strength, the T-girders is short for Transverse girders and L-girders is short for Longitudinal girders).

Table 1.Material Parameters

\begin{tabular}{|c|c|c|c|c|c|c|c|c|}
\hline \multirow[b]{2}{*}{ Members } & \multicolumn{4}{|c|}{ Concrete } & \multicolumn{4}{|c|}{ Steel } \\
\hline & $\begin{array}{c}\text { Strength } \\
{[\mathrm{MPa}]}\end{array}$ & $\begin{array}{c}\text { Tensile } \\
\text { limit } \\
{[\mathrm{MPa}]}\end{array}$ & $\begin{array}{c}\text { Young's } \\
\text { modulus } \\
{[\mathrm{GPa}]}\end{array}$ & $\begin{array}{l}\text { Poisson's } \\
\text { ratio }\end{array}$ & $\begin{array}{c}\text { Yield } \\
\text { stress } \\
{[\mathrm{MPa}]} \\
\end{array}$ & $\begin{array}{c}\text { Young's } \\
\text { modulus } \\
{[\mathrm{GPa}]}\end{array}$ & $\begin{array}{c}\text { Hardening } \\
\text { modulus } \\
{[\mathrm{GPa}]}\end{array}$ & $\begin{array}{c}\text { Failure } \\
\text { strain }\end{array}$ \\
\hline Slabs & 27 & 2.7 & 2.88 & 0.2 & 390 & 210 & 230 & 0.1 \\
\hline Columns & 27 & 2.7 & 2.88 & 0.2 & 310 & 210 & 230 & 0.1 \\
\hline T-girders & 27 & 2.7 & 2.88 & 0.2 & 310 & 210 & 230 & 0.1 \\
\hline L-girders & 27 & 2.7 & 2.88 & 0.2 & 310 & 210 & 230 & 0.1 \\
\hline
\end{tabular}

Table 2. Reinforcement Ratio

\begin{tabular}{cccc}
\hline Slabs & columns & T- girders & L- girders \\
\hline $1.54 \%$ & $2.10 \%$ & $1.82 \%$ & $1.12 \%$ \\
\hline
\end{tabular}

It is why alternate path method used to simulate the sudden column ZB3 loss that the duration of blast load is too short and the effect on other sections isn't obvious, at the same time, the assumption that the bearing capacity of column ZB3 lost completely is made.

Compare the results of numerical simulation with the experimental results to verify the validity of the model. Because of the initial micro-crack and initial damage, the collection of the exponential decay of the amplitude is always difficult, so choose the peak and the stable value which are marked by the dashed box to compare. The displacement curve is shown in Fig.2, and the displacement nephogram when the displacement reaches the peak is shown in Fig.3. It can be seen that the displacement variation trend of column $\mathrm{ZB} 3$ is consistent with the experiment. In the experiment, the peak of vertical displacement of column ZB3 is $6.11 \mathrm{~mm}$, and the stable value is $2.7 \mathrm{~mm}$, in the numerical simulation, the peak of vertical displacement is $5.66 \mathrm{~mm}$, and the stable value is $2.85 \mathrm{~mm}$, the error of the peak is $0.44 \mathrm{~mm}(7.2 \%)$, the error of stable value is $0.15 \mathrm{~mm}(5.6 \%)$, the displacement value of column ZB3 is basically consistent with the experiment. Reasonable prediction of the 
collapse performance of RC frame structure under blast load can be given by the model.

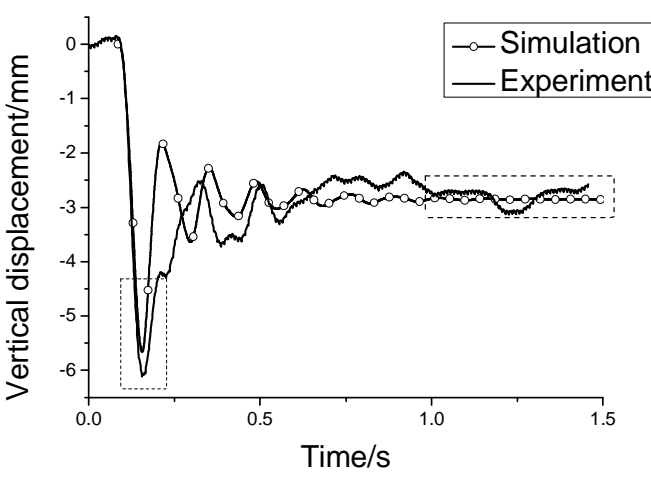

Fig.2Displacement of Column ZB3

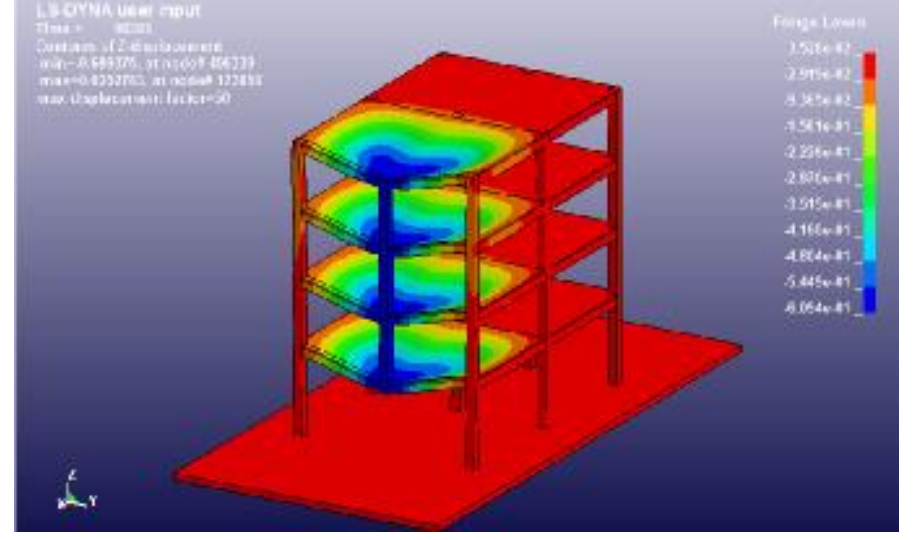

Fig. 3 the displacement nephogram when the displacement reaches the peak

Parameter Analysis. The strength of concrete and the reinforcement ratio are the important factors which influence the strength of reinforced concrete. The influence of concrete strength and reinforcement ratio on the progressive collapse performance of frame structure is studied in this paper.

Strength of Concrete. Keep the parameters of the steel bar unchanged, increase the concrete strength by $10 \%$ and $20 \%$, reduce the strength of the concrete by $10 \%$ and $20 \%$. The rest parameters are selected according to the Code for design of concrete structures ${ }^{[7]}$. The displacement of column ZB3 is shown in Table 3, the displacement-time curve is shown in Fig.4.

Table 3.Concrete Parameters after Change and Displacement of Column ZB3

\begin{tabular}{ccccccc}
\hline $\begin{array}{c}\text { Changing } \\
\text { amplitude }\end{array}$ & $\begin{array}{c}\text { strength } \\
{[\mathrm{MPa}]}\end{array}$ & $\begin{array}{c}\text { Tensile } \\
\text { limit } \\
{[\mathrm{MPa}]}\end{array}$ & $\begin{array}{c}\text { Young's } \\
\text { modulus } \\
{[\mathrm{GPa}]}\end{array}$ & $\begin{array}{c}\text { Poisson's } \\
\text { ratio }\end{array}$ & $\begin{array}{c}\text { Peak } \\
{[\mathrm{mm}]}\end{array}$ & $\begin{array}{c}\text { Stable value } \\
{[\mathrm{mm}]}\end{array}$ \\
\hline$+20 \%$ & 32.4 & 3.24 & 3.07 & 0.2 & 5.21 & 2.55 \\
$+10 \%$ & 29.7 & 2.94 & 2.99 & 0.2 & 5.41 & 2.70 \\
$-10 \%$ & 24.3 & 2.43 & 2.77 & 0.2 & 5.91 & 3.03 \\
$-20 \%$ & 21.6 & 2.16 & 2.63 & 0.2 & 6.26 & 3.30 \\
\hline
\end{tabular}

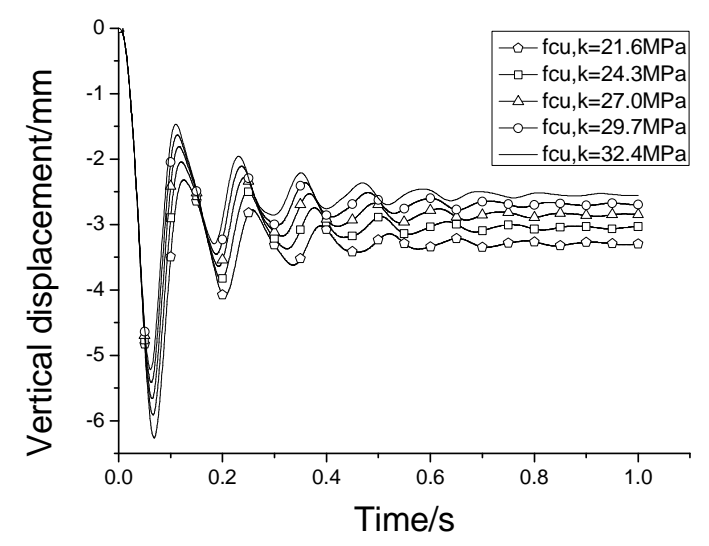

Fig.4 Displacement-time curve of different concrete strength

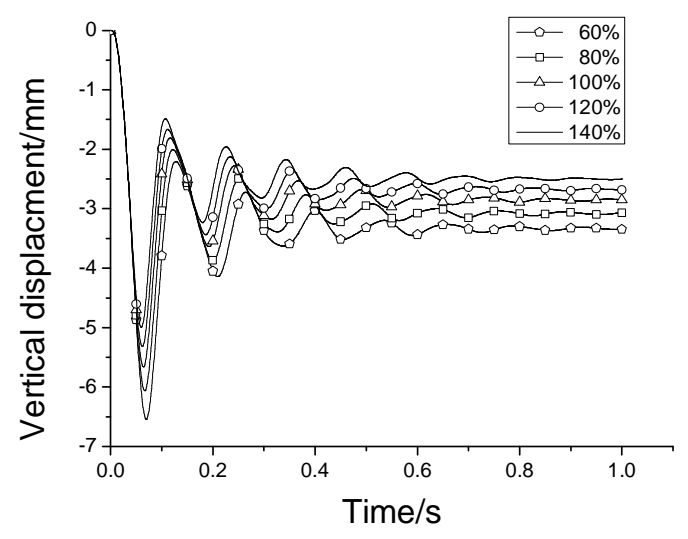

Fig.5 Displacement-time curve of different reinforcement ratio

The peak and stable value of displacement decrease as the increasing of strength of concrete can be learnt from Table 3 and Fig.4. It can be speculated that the progressive collapse resistant capacity can be improved by improving the concrete strength.

Reinforcement Ratio. Keep the parameters of concrete and steel unchanged, increase the reinforcement ratio by $20 \%$ and $40 \%$, reduce the ratio by $20 \%$ and $40 \%$. The displacement of column ZB3 is shown in Table 4, the displacement-time curve is shown in Fig.5. 
Table 4. Reinforcement Ratio after Change and Displacement of Column ZB3

\begin{tabular}{ccccccc}
\hline $\begin{array}{c}\text { Changing } \\
\text { amplitude }\end{array}$ & Slabs & columns & T- girders & L- girders & Peak [mm] & $\begin{array}{c}\text { Stable value } \\
{[\mathrm{mm}]}\end{array}$ \\
\hline$+40 \%$ & $1.54 \%$ & $2.10 \%$ & $1.82 \%$ & $1.12 \%$ & 4.99 & 2.50 \\
$+20 \%$ & $1.32 \%$ & $1.80 \%$ & $1.56 \%$ & $0.96 \%$ & 5.31 & 2.68 \\
$-20 \%$ & $0.88 \%$ & $1.20 \%$ & $1.04 \%$ & $0.64 \%$ & 6.06 & 3.07 \\
$-40 \%$ & $0.66 \%$ & $0.90 \%$ & $0.78 \%$ & $0.48 \%$ & 6.55 & 3.35 \\
\hline
\end{tabular}

The peak and stable value of displacement decrease as the increasing of reinforcement can be learnt from Table 4 and Fig.5. The progressive collapse resistant capacity can be improved by improving the Reinforcement Ratio.

According to Table 3 and Table 4, it is obvious that the strength of concrete and the reinforcement ratio don't have significantly influence on the progressive collapse resistant capacity basing on the model in this paper.

Critical Load and Dynamic Amplification Factor (DAF). According to DoD 2005 ${ }^{[8]}$, progressive collapse of structures take place when the rotation of structural members reach 11.3-deg. The progressive collapse of the model in this study occurs when the displacement of column ZB3 reach $246.6 \mathrm{~mm}$. Keep the parameters of concrete and steel unchanged, change the load to double design load, 3 times of the design load and 3.25 times of the design load, the displacement nephograms when the displacement reaches the stable value or $246.6 \mathrm{~mm}$ is shown in Fig.6, the displacement of column ZB3 is shown in Table 5.

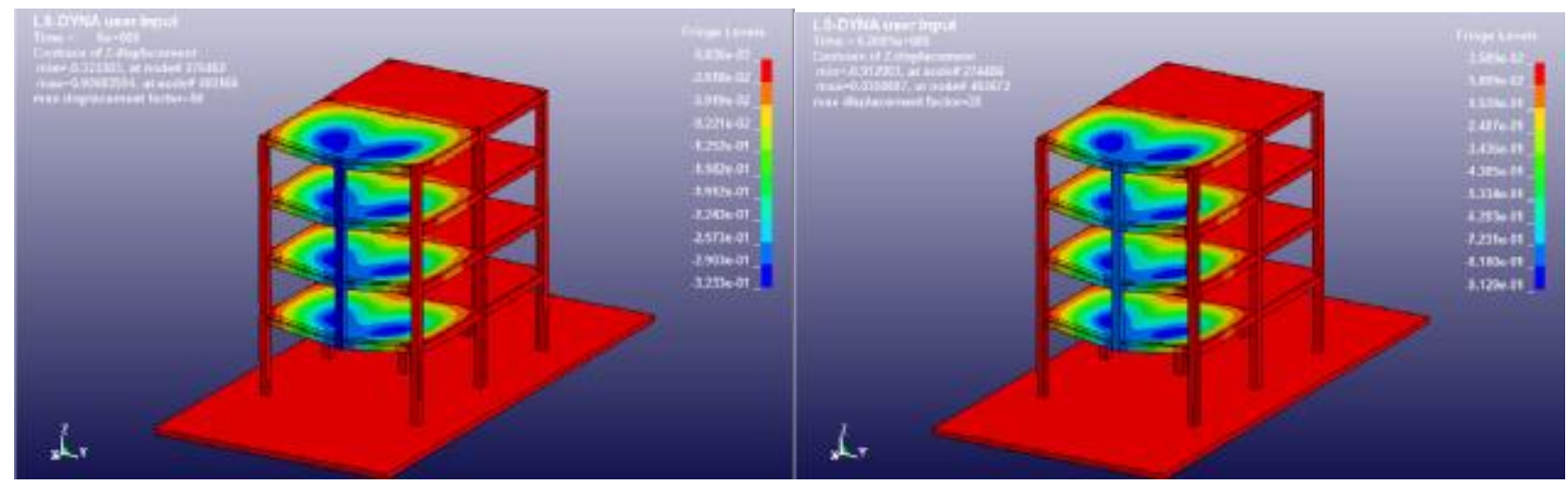

(a)Design load

(b) Double design load

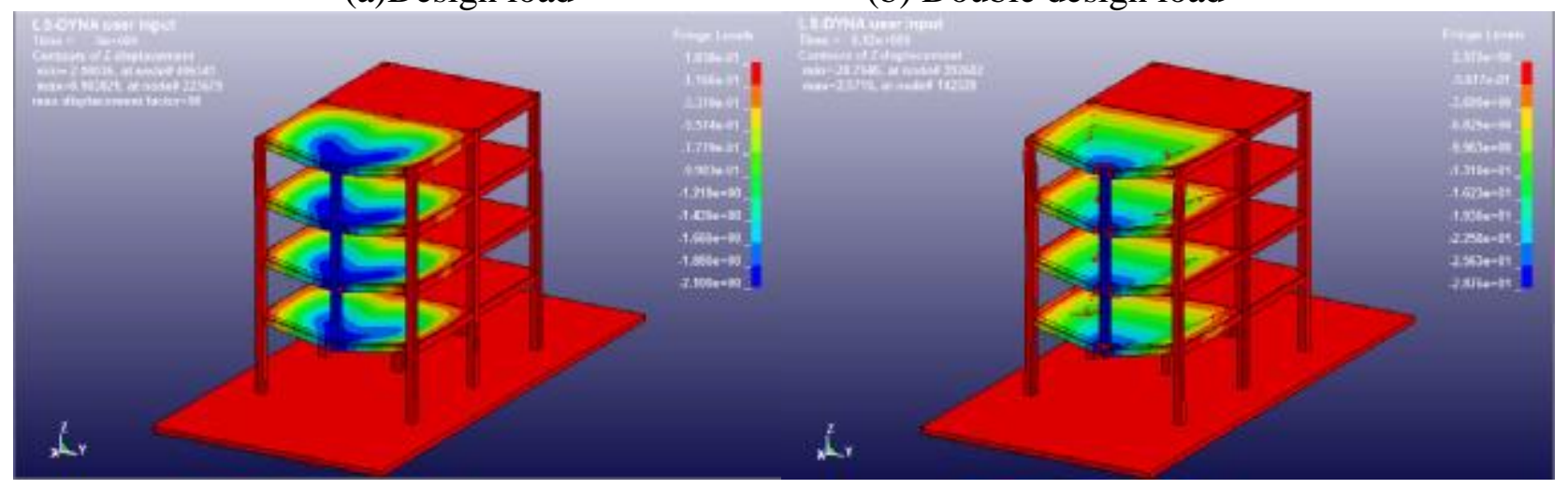

(c) 3 times of the design load

(d) 3.25 times of the design load

Fig.6 Displacement nephograms under different load

After a lot of calculation, we can find that the displacement of column ZB3 reaches $28.5 \mathrm{~mm}$ and remains stable when the load reach 3.15 times of the design load, the displacement increases until the progressive collapse occurs when the load reach 3.16 times of the design load. It can be found that the critical load of the frame structure would be 3.15 times of the designing load. 
Table 5 Displacement of ZB3 under different load

\begin{tabular}{ccccc}
\hline Multiple of design load & 1 & 2 & 3 & 3.25 \\
\hline Displacement[mm] & 5.66 & 7.50 & 20.4 & 250 \\
State & Stable & Stable & Stable & Unstable \\
\hline
\end{tabular}

Amplify the above critical load by a factor and treat the new load as static to find the DAF. To avoid dynamic response, the load is gradually added to the target value as the sine curve which is shown in Fig. $7^{[9]}$. Treat 1 as the initial DAF and add 0.01 every time, then calculate using ANSYS/LS-DYNA. It can be found that the displacement of column ZB3 reaches $19.3 \mathrm{~mm}$ and remains stable when the DAF reaches 1.32 , the displacement reaches $246.6 \mathrm{~mm}$ at $530 \mathrm{~ms}$ when the DAF reaches 1.33 . The displacement nephogram at 530ms is shown in Fig.8. It can be found that the critical load of the DAF would be 1.32 .

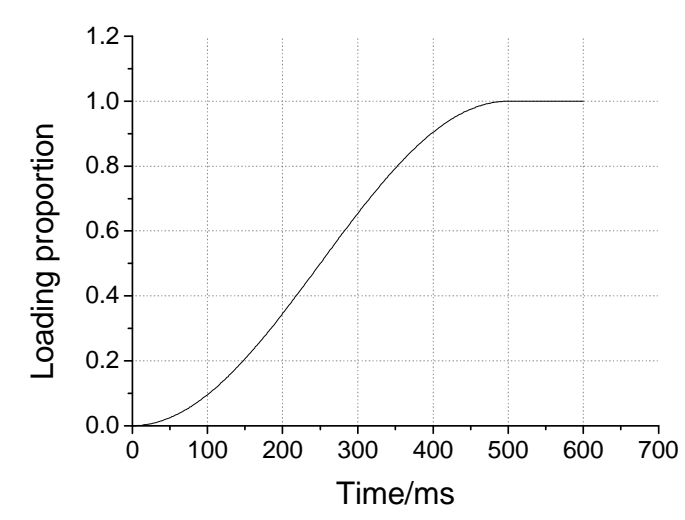

Fig.7 Loading curve

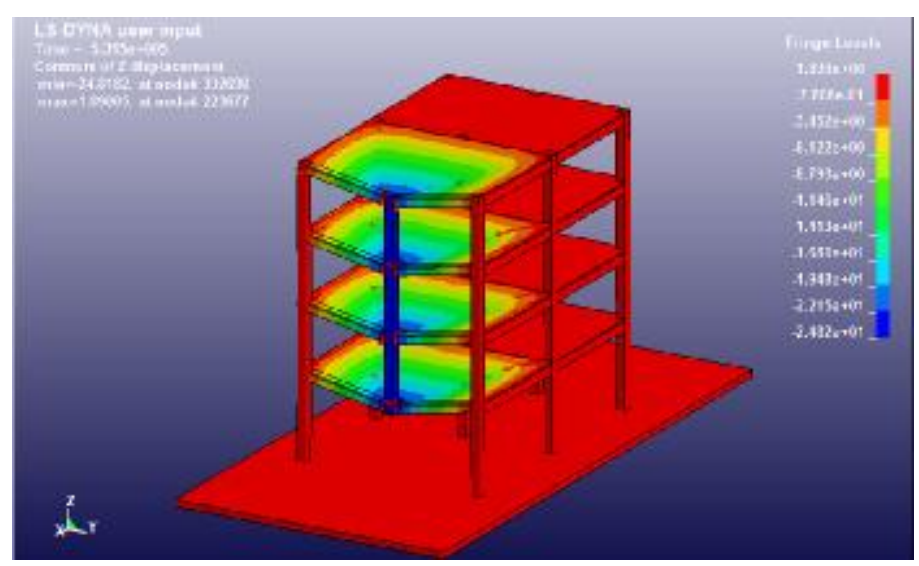

Fig.8 Displacement nephogram at 530ms

Safety Evaluation of DoD 2005. The design load in DoD 2005 is considered as Eq.1:

$\mathrm{G}_{\mathrm{LF}}=\Omega_{\mathrm{LF}}(1.2 \mathrm{D}+0.5 \mathrm{~L})$

$\mathrm{G}_{\mathrm{LF}}$ : Increased load for Linear Static Analysis.

D: Dead load including façade loads.

L: Live load.

$\Omega_{\mathrm{LF}}$ : Load increase factor.
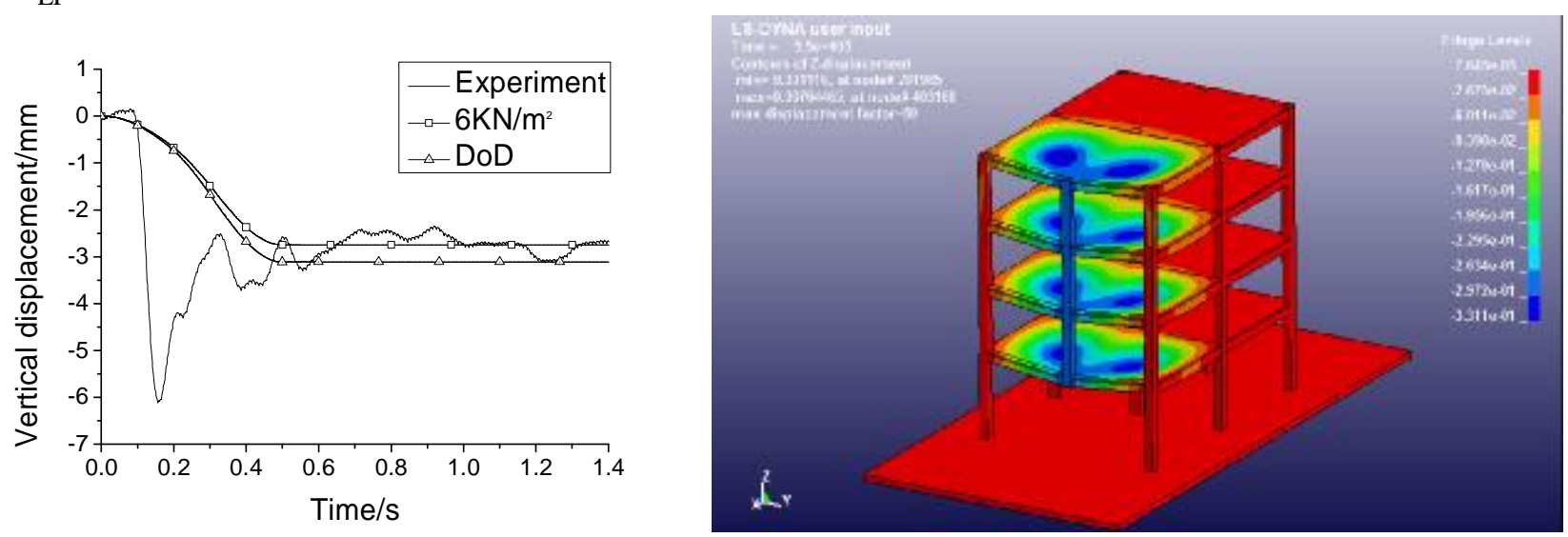

Fig.9 Displacement under different loads Fig.10 Displacement nephogram under increased load

In the experiment, the dead load is $2.5 \mathrm{KN} / \mathrm{m}^{2}$, the live load is $2 \mathrm{KN} / \mathrm{m}^{2}$, it can be found that the $\mathrm{G}_{\mathrm{LF}}$ is $7.4 \mathrm{KN} / \mathrm{m}^{2}$ by calculating. The increased load is gradually added to the target value as the sine curve. The displacement of column ZB3 under different load is shown in Fig.9, the cloud graph of final displacement under increased load is shown in Fig. 10.

It can be seen that the final displacement of column ZB3 under the increased load is $3.11 \mathrm{~mm}$, which is a little larger than the actual displacement. It is believed that there is a certain degree of safety 
redundancy. The peak displacement of column ZB3 in the experiment reached $6.11 \mathrm{~mm}$, which was not fully considered in the DoD 2005. It can be concluded that the peak of displacement isn't fully considered in the DoD 2005, so the method is dangerous.

\section{Conclusions}

The following conclusions can be learnt according to the above studies:

(1) The progressive collapse resistant capacity can be improved by improving the concrete strength and longitudinal reinforcement ratio, but there are not significant influences;

(2) The critical load of the frame structure would be 3.15 times of the designing load and the DAF of 1.32 is found;

(3) The peak of displacement isn't fully considered in the DoD 2005.

\section{References}

[1] Pearson C, Delatte N.Ronan Point Apartment Tower Collapse and its Effect on Building Codes.Journal of Constructed Facilities,2005,19(2):172-177.

[2] Corley W G,Mlakar P E,Sozen M A, Thornton C H. The Oklahoma City Bombing:Summary and Recommendations for Multihazard mitigation. Journal of Performance of Constructed Facilities, 1998,12(3):100-112.

[3] Shi Yan-chao, Numerical analysis of progressive collapse of reinforced concrete frame under blast loading.Journal of PLA University of Science and Technology(Natural Science Edition), 2007, 8(6).

[4] Li Zhong-xian. Damage analysis and assessment of RC slabs under blast load. Journal of Building Structures,2009,30(6).

[5] Yi Wei-jian, Experimental study on collapse performance of a RC flat plate frame structure. Journal of Building Structures,2012,33(6).

[6] He Qing-feng. Research on Progressive Collapse Behavior of RC Frame Structures [D].Changsha: Hunan University,2009.

[7] GB 50010-2010, Code for design of concrete structures, 2015

[8] Design of building to resist progressive collapse, UFC 4-023-03,2005.

[9] Gumruk R, Karadeniz S The influences of the residual forming data on the quasi-static axial crash response of a top-hat section. International Journal of Mechanical Sciences,2009,51:350-362. 